\title{
JURISPRUDENCIA PENAL AMBIENTAL \\ (PRIMER SEMESTRE 2020)
}

\author{
MARIA MARQUĖS I BANQUÉ \\ Profesora agregada de Derecho Penal \\ Universitat Rovira i Virgili \\ NÚRIA TORRES ROSELL \\ Profesora agregada Serra Húnter de Derecho Penal \\ Universitat Rovira i Virgili
}


Sumario: 1. Delitos relativos a la ordenación del territorio y el urbanismo. 2. Delitos contra los recursos naturales y el medio ambiente. 3. Delitos relativos a la protección de la flora, la fauna y los animales domésticos.

\section{DELITOS RELATIVOS A LA ORDENACIÓN DEL TERRITORIO Y EL URBANISMO}

En materia de delitos sobre la ordenación del territorio, durante los últimos meses se han dictado algunas sentencias de Audiencias Provinciales que, básicamente, confirman criterios jurisprudenciales muy consolidados.

Así, por ejemplo, la SAP Badajoz (Sección 1ํㅜ) núm. 121/2019, de 16 de diciembre, confirma la sentencia de instancia por la que se condena al acusado por un delito del artículo 319.2 y 3 CP. La Sala descarta la concurrencia de error de prohibición invencible o vencible por parte del autor, en un supuesto de construcción de una vivienda de dos plantas en una parcela sita en suelo no urbanizable, con licencia para construir únicamente una caseta de aperos de labranza que, entre otras condiciones, no podía superar los 20 metros cuadrados. La Sala estima que "resulta sencillamente inaceptable la versión con la que se pretende justificar un error al 'pensar que se trataba de una licencia para cualquier construcción', máxime si -como inevitablemente reconoce- se le notificó Resolución de la Alcaldía para paralizar la obra". La licencia para construir una simple construcción para aperos, se considera que "fue ostensiblemente incumplida, desbordada en extensión, límites y condiciones de autorización, de forma renuente y con pleno conocimiento (...) Se excluye de forma rotunda, conforme a las circunstancias acreditadas y las que hemos consignado más arriba, la posibilidad de que la actuación del recurrente no fuera dolosa, o que lo fuera simplemente imprudente, pues en todo momento fue conocedor de la ilicitud de su proceder y a pesar de ello -y de los requerimientos y visitas- llevó a cabo la construcción ilegal en terreno no urbanizable". En el mismo sentido y con cita abundante de jurisprudencia, se pronuncian la SAP Castellón (Sección $2^{\mathrm{a}}$ ) núm. 440/2019, de 16 de diciembre y la SAP Jaén (Sección 3a) núm. 363/2019, de 27 de noviembre.

Con relación al sujeto activo del delito, la SAP Badajoz (Sección 1aㅡ) núm. $121 / 2019$, de 16 de diciembre, confirma que el recurrente ostenta la cualidad de promotor a los efectos de ser considerado autor del delito, pues "la norma no 
exige cualificación técnica o profesional, pudiendo serlo cualquier persona, física o jurídica, pública o privada, que, individual o colectivamente, deciden, impulsan, programan y financian con recursos propios o ajenos, las obras de edificación para sí o para su posterior enajenación, entrega o cesión a terceros bajo cualquier título". En este mismo sentido se pronuncia la ya citada SAP Castellón (Sección $2^{a}$ ) núm. 440/2019, de 16 de diciembre, que con relación a las demás sujetos activos del delito, recuerda que "tanto el proyectista como los directores precisan estar en posesión de la correspondiente titulación académica y profesional habilitante" y que el constructor "deberá tener la titulación o capacitación profesional que habilita para el cumplimiento de las condiciones exigibles para actuar como constructor. (...) Ello significa que sólo los técnicos deben poseer la titulación que profesionalmente les habilite para el ejercicio de su función, mientras que el promotor, sea o no propietario, no precisa condición profesional alguna, y los constructores sólo precisan la mera capacitación profesional". Esta sentencia, todavía descarta el argumento relacionado con la supuesta incompatibilidad entre la no exigencia de profesionalidad del promotor y la pena de inhabilitación especial para profesión u oficio prevista en este delito, recordando que la previsión de tal pena "no puede excluir a las personas que promuevan o construyan sin licencia o excediéndose de la concedida, y que no sean profesionales, de la autoría del delito, pues no deja de tener sentido dicha inhabilitación aún en dicho caso, puesto que tales actividades están sujetas al régimen de licencia y autorización y ello ya comporta una relación con la Administración de que se trate, inhabilitación que conforme a lo dispuesto en el artículo 45 CP deberá concretarse expresa y motivadamente en la sentencia".

Con relación a la demolición acordada por la sentencia de instancia, la SAP Badajoz (Sección 1ª ) núm. 121/2019, de 16 de diciembre, confirma su procedencia sobre la base de la jurisprudencia que considera la demolición como "la única medida posible para restaurar el daño causado al bien jurídico protegido porque de otra forma se perpetraría el daño causado sin solución, lo que supondría la ineficacia de la finalidad preventiva que pretende la norma" e interpreta el carácter opcional de la medida con la discrecionalidad, pero no con la excepcionalidad: "Será precisa la demolición, para que la realidad física alterada vuelva al estado inmediatamente anterior a la intervención ilegal, de 
modo que habrán de ser, en su caso, circunstancias excepcionales, las que puedan llevar al Tribunal a ejercer la facultad que le atribuye I apartado 3 del artículo 319 del Código Penal en el sentido de no acordar la demolición”. En el mismo sentido se pronuncia la citada SAP Jaén (Sección 3aㅗ núm. 363/2019, de 27 de noviembre, que admite haber cambiado el criterio aplicado en el pasado ante la "reiteradísima doctrina jurisprudencial que señala de forma contundente que la norma general ha de ser la demolición, la cual debe acordarse cuando conste patentemente que la construcción está completamente fuera de la ordenación, y no es legalizable o subsanable o en aquellos supuestos en que haya existido una voluntad rebelde del sujeto activo del delito a las órdenes o requerimientos de la Administración".

La SAP Murcia (Sección 3ª̣) núm. 378/2019, de 21 de noviembre, aborda la trascendencia de la posible legalización posterior de una obra en la interpretación del elemento típico "no autorizable". En el caso enjuiciado los condenados quisieron regularizar la situación de su propiedad afectada a través de la adquisición de fincas colindantes, con las que se cumplimentaría el requisito de parcela mínima y de retranqueo. No obstante, con base en jurisprudencia del TS y de Audiencias Provinciales, la Sala recuerda que "la expresión no autorizable no alude a la eventualidad de que, en un futuro, más o menos incierto o lejano, pudiera modificarse la legalidad urbanística. Esta interpretación nos lleva al absurdo: por vía de hipótesis y en abstracto toda calificación es susceptible de modificación por decisión del legislador o de la administración competente en materia urbanística. Ese elemento del tipo se refiere a la ilegalidad material de la edificación cuando se realiza, por no ajustarse a la ordenación. No basta que se haya levantado sin licencia; es necesario que sea contraria a la legalidad urbanística vigente en ese momento (...) Solo las modificaciones legislativas que obedecen a verdaderos cambios valorativos -el legislador opina que no es necesario seguir protegiendo del mismo modo un determinado bien jurídico o que determinado comportamiento ya no es lesivo para el bien jurídico de manera que no se mantiene la necesidad político criminal de un concreto tipo delictivo-, deben aplicarse retroactivamente si son favorables".

Con relación al bien jurídico protegido por el artículo 319 CP y su delimitación con la infracción administrativa, cabe destacar la SAP Tarragona (Sección 4ª ) 
núm. 388/2019, de 5 de noviembre: "...lo anterior nos permite aproximarnos al contenido del bien jurídico que se protege mediante el artículo $319 \mathrm{CP}$ que no es la normativa urbanística, sino el valor material de ordenación del territorio entendido como utilización racional del suelo orientado a los intereses generales o como adecuación de su uso al interés general, partiendo de su condición de recurso natural limitado. Por tanto, el objeto y los fines de protección no se miden por la correspondencia entre edificación y condiciones de la licencia para edificar. Las desviaciones del marco de la autorización son, prima facie, protegibles y reparables por la normativa administrativa sectorial. Incluso, la edificación sin licencia realizada en suelo no urbanizable, cuando no afecta a espacios protegidos o de especial relevancia como los precisados en el apartado primero del artículo 319_CP, no pasa necesariamente por la sanción penal. Por tanto, lo que se castiga, porque lesiona el bien jurídico, son las acciones constructivas en un suelo no urbanizable que, en atención al cómo se construye, al qué se construye, al dónde se construye o por quién se construye infringen de forma nuclear los fundamentos, no de la disciplina urbanística sino de la ordenación urbanística que garantiza el uso racional, controlado, sometido a un proceso de transparencia en la autorización y en el control de la ejecución, garantizando la igualdad de todos los ciudadanos y ciudadanas en el acceso y uso del suelo".

En lo que concierne al delito de prevaricación ambiental del artículo $320 \mathrm{CP}$ destaca, en el periodo temporal de análisis que abarca esta crónica, la STS (Sección 1a) núm. 436/2019, de 14 octubre. La resolución confirma la sentencia condenatoria dictada por la Audiencia Provincial de Almería el 30 de junio de 2017 y en la que se enjuiciaba una larga y compleja actividad protagonizada por diversos sujetos, entre los cuales, el alcalde y el concejal delegado de urbanismo de la localidad de Zurgena. Entre tales comportamientos destacan especialmente los siguientes: entre los años 2003 y 2005 los acusados concedieron licencias para viviendas en suelo no urbanizable, a sabiendas de que eran contrarias a la normativa urbanística. En algunos expediente administrativos se emitió informe técnico contrario a la concesión de la licencia y en otros se prescindió del informe técnico e incluso de este y del informe jurídico. En segundo lugar, en los años 2005 y 2006 los acusados procedieron a conceder una serie de licencias de segregación de fincas rústicas situadas en suelo no 
urbanizable con conocimiento de que se estaba autorizando auténticas parcelaciones urbanísticas y que la ley prohíbe las parcelaciones urbanísticas en suelo no urbanizable. Estas licencias las concedían prescindiendo total y absolutamente del procedimiento administrativo establecido pues en ninguna de las que a continuación se relacionarán se emitieron los preceptivos informes jurídicos. Todavía en un tercer bloque de actividad se describe la concesión, por parte del alcalde, de un conjunto de licencias de construcción que ya no fueron autorizadas por el pleno del ayuntamiento y que el alcalde quiso conceder sin necesidad de firmarlas. Para ello, voluntariamente se dejaban transcurrir tres meses desde la petición de concesión de la licencia sin dictar ninguna resolución al respecto, certificándose su concesión por silencia administrativo transcurrido ese plazo. Los certificados estaban firmados por el alcalde de Zurgena y por la secretaria del Ayuntamiento. En estos certificados se dejaba constancia de que habían transcurrido tres meses desde la solicitud sin que se hubiera notificado una resolución, indicándose que el silencio administrativo tenía un sentido positivo de conformidad con el artículo 172.5 de la Ley 7/2002, de 17 de diciembre, de Ordenación Urbanística de Andalucía. Con ello se contrariaban los informes que con anterioridad había emitido la secretaria del Ayuntamiento, en los que establecía que el silencio administrativo en estos supuestos no debe tener un sentido positivo, pues a las licencias que fueran disconformes con la ordenación urbana debe aplicárseles el procedimiento de revisión de oficio regulado en la Ley $7 / 2002$, de Andalucía. De este modo, se concedieron 30 licencias que permitían la construcción de 155 viviendas.

La resolución del Tribunal Supremo admite la concurrencia del delito de prevaricación urbanística en el caso enjuiciado y fija algunas cuestiones clave para ello. Así sostiene que "(I)os hechos que se sancionan no solo comportaron la omisión o el fraude de todos los elementos de control de la legalidad urbanística, tales como clasificación del suelo, los informes jurídicos, los informes técnicos o a los propios organismos establecidos para el control y supervisión de la promoción urbanística, incluyendo las propias funciones que correspondían a los acusados, sino que lo hicieron: por un largo tiempo; con una gran cantidad de licencias emitidas en ese periodo; y en favor de una pluralidad de entidades empresariales para las que la promoción constituía su objeto social". En efecto, 
la sentencia de instancia destaca que fueron "centenares las viviendas promovidas, con una profunda modificación de importantes espacios de terreno rústico, los cuales fueron intensamente urbanizados y construidos, generando así una radical y extensa alteración de la morfología del espacio público circundante a la población de Zurgena, así como del aprovechamiento de su suelo." Por todo ello concluye el alto tribunal que el comportamiento de los recurrentes "introdujo las alteraciones que la legalidad urbanística pretende conducir conforme a criterios e intereses más amplios que los municipales y, superando la operatividad de estas normas así como sus ordinarios mecanismos de limitación y control, rompió definitivamente la ordenación del territorio que surgiría de los principios y normas transgredidos." Por todo ello, la sentencia mantiene la condena a los acusados por el delito de prevaricación urbanística, por el delito contra la ordenación del territorio del art. 319.2 CP, por el delito de falsedad en documento oficial y por el delito de cohecho, si bien los absuelve por el delito de negociaciones prohibidas a los funcionarios del artículo $439 \mathrm{CP}$.

La segunda sentencia que cabe mencionar en relación con el delito de prevaricación urbanística es la dictada por el Juzgado de lo Penal de Santander, núm. 3 , de 30 de diciembre de 2019, por la que se condena por un delito continuado de prevaricación del artículo 404 CP así como por delito de prevaricación urbanística del artículo 320 CP a quien fuera Alcalde del Ayuntamiento de Castro Urdiales y a la ingeniera municipal por conductas consistentes operaciones de recalificación urbanística efectuadas en el municipio. Estas recalificaciones llevaron a un desarrollo del municipio no deseable, conforme a las finalidades constitucionalmente previstas, de uso racional del suelo y del medio ambiente, con respeto del interés y atendiendo al beneficio de la comunidad.

Entre los hechos probados se señala que la Corporación municipal y la comisión de Urbanismo pretendieron desde al menos el año 2001, abrir nuevos viales públicos en terrenos donde el PGOU no lo preveía, y frente al reproche contenido en informes "reiterados, contundentes y concluyentes en sentido desfavorable" del supervisor de legalidad urbanística en los que se sostenía que "la pretensión de abrir nuevos viales no responde al interés general e implica disminución de equipamientos públicos pretendiendo dar solución a problemas generados por 
falta de rigurosidad y control". Como señala la sentencia "la cuestión litigiosa, al margen de la discutida distinción, entre sistemas generales y locales, a los viales de dicha naturaleza, públicos o privados, o a la de los usos pormenorizados o compatibles, se reduce en realidad a la evidencia constatada de la apertura de un vial, no interior mediante ED, cuando carecía de aquella capacidad, por no encontrarse previsto en el $\mathrm{PG}$, invadiendo parcialmente terrenos de equipamiento deportivo, reduciendo la superficie dotacional que aquel establecía, así como las cesiones al respecto que fijaba en los mismos, convirtiéndolos en viario, trasladándolos en parte aquellos a la zona residencial, segregando la superficie inicialmente prevista, desoyendo la compensación dotacional requerida y en las condiciones exigidas, en los vinculantes dictámenes desfavorables de la CROTU, en las modificaciones intentadas del PGOU, en las que el Ayuntamiento, lo que solicita desde el primer momento y efectivamente realiza es la apertura de viales, que afectan y conectan varias unidades de ejecución, cambiando la calificación del terreno dotacional de equipamiento que atraviesa, disminuyendo su superficie".

En relación con el delito de prevaricación urbanística del artículo $320 \mathrm{CP}$, la resolución recoge la especialidad de este tipo penal respecto del genérico de prevaricación, si bien en este caso "la injusticia de la resolución debe venir de la vulneración de la legalidad urbanística aplicable al caso, ya sean unas normas subsidiarias, ya normas con rango de Ley, y ya en cuanto al fondo de la resolución, ya en cuanto a la competencia o el procedimiento, pues todas ellas constituyen el derecho urbanístico aplicable".

En el caso concreto se considera cometido el delito de prevaricación urbanística por cuanto "la concesión de licencia por el Sr. Sebastián, con el informe favorable de la Sra. Evangelina, integra la prevaricación urbanística que se les imputa, del art 320.2 y 1 respectivamente del Código Penal, en la fecha de comisión de los hechos, el cual tras la posterior reforma por Ley Orgánica 5/2010, incluye además los instrumentos de planeamiento, los proyectos de urbanización, parcelación, reparcelación, construcción o edificación o la concesión de las licencias, que resultan punibles conforme a la misma desde aquella, y no antes. Así el informe de la licencia y su otorgamiento, integran la prevaricación urbanística especial del art. 320, estando sancionados los anteriores, así como 
los acuerdos y resoluciones del Alcalde previos en la prevaricación genérica del art. 404". Y prosigue la sentencia diciendo que "el art. 320 no tipifica una mera irregularidad administrativa o la contrariedad a la norma urbanística, pues resulta esencial que la conducta ponga en peligro el bien jurídico protegido, la ordenación del territorio, como dispone la STS de 27-11-09, encontrándose una relación de especialidad con el art 404, dándose respecto al mismo una secuencia dentro de un plan unitario desde la aprobación de los proyectos, hasta la concesión de las licencias, con las mismas contravenciones, resultando una continuación en su actuación prevaricadora."

\section{DELITOS CONTRA LOS RECURSOS NATURALES Y EL MEDIO AMBIENTE}

En el periodo temporal de referencia de esta crónica cabe destacar cinco sentencias relativas a delitos contra los recursos naturales y el medio ambiente. Cuatro de los pronunciamientos se refieren al art. 325 CP (en su modalidad de contaminación acústica y vertidos) y una de ellas al art. 326.1 CP (gestión de residuos).

La primera sentencia sobre contaminación acústica es la SAP Madrid (Sección 30a) núm. 661/2019, de 15 de noviembre. Los hechos se refieren al ruido causado desde un domicilio particular por una persona afectada por un trastorno límite de la personalidad y una minusvalía reconocida del 92 o 93 por ciento. De acuerdo con los hechos probados, desde el año 2012, la acusada comenzó una actividad consistente en activar reproductores del sonido a un elevadísimo volumen apto para ser oídos por los vecinos del inmueble e inmueble contiguo, todo ello de modo indiscriminado, de día y de noche. Como consecuencia de estos hechos, una vecina tuvo que recibir tratamiento psiquiátrico por padecer trastorno ansioso-depresivo reactivo a dichos ruidos, y otro vecino padeció trastorno ansioso- depresivo, necesitado de tratamiento médico especializado, persistiendo ambas patologías en el momento de celebración de la vista oral.

A pesar de que los hechos se remonten a 2012, se estima de aplicación la redacción del CP vigente, en vigor desde el 1 de julio de 2015, pues prácticamente todas las mediciones se realizaron con posterioridad y las declaraciones de los testigos se refieren a hechos posteriores a la entrada en 
vigor de la reforma penal de 2015.

Los hechos descritos como probados se consideran constitutivos, en primer lugar, de un delito contra el medio ambiente del artículo 325, con la agravación prevista en el párrafo segundo del apartado segundo de dicho precepto. Con relación a la interpretación del artículo $325 \mathrm{CP}$, la sentencia no aporta ninguna novedad significativa. Remitiéndose a jurisprudencia anterior, afirma: "El tipo penal del artículo 325 se presenta como un tipo de estructura compleja cuya base es la infracción de ordenamiento que sobrepasa los límites de lo permitido, requiriendo que sanción que infringe el ordenamiento se ha valorado como perjudicial para lo que es preciso acudir a la normativa específica, en este caso emanadas del ayuntamiento, que regula el ámbito de lo permitido por la actividad industrial para compaginar lo con el derecho a una convivencia ordenada. Por otra parte desde la tipicidad subjetiva, el dolo este delito consiste en el conocimiento de que la acción realizada, en el caso las emisiones acústicas genera un riesgo grave en el bien jurídico lo que comporta la existencia de una voluntariedad en la causa acción de riesgo y la representación de interacción puede generar los perjuicios que en el caso se declaran probados, lo que se corrobora cuando conociendo el incumplimiento de la norma, conociendo el resultado producido, no se desiste de la acción y el resultado perturbador se mantienen en tiempo. Se trata de conductas delictivas de peligro hipotético, de peligro abstracto-concreto reprochando sé penalmente un comportamiento idóneo para producir un peligro para el bien jurídico protegido. Normalmente, será un dolo eventual ya que la conducta lesiva del medio ambiente se limitará a poner en peligro como resultado de la acción el bien jurídico con conocimiento de la acción que se desarrolla y la potencialidad de riesgo".

El peligro potencial para la salud de las personas se considera materializado en dos hechos: las continuadas y graves molestias a los vecinos del propio inmueble y del colindante; y la causación de las lesiones descritas en los hechos probados a dos vecinos.

De acuerdo con la Sala y siguiendo un criterio jurisprudencial consolidado, estas lesiones, además de evidenciar el potencial lesivo de la conducta de la acusada, son constitutivas de dos delitos de lesiones del artículo 147.1 CP en su 
modalidad dolosa, pues "desde un concepto normativo del dolo basado en el conocimiento de que la conducta que se realiza pone en peligro el bien jurídico protegido, el dolo se integra por ese conocimiento de la potencialidad lesiva en el empleo de los medios que son utilizados y del que es previsible la causa acción del resultado típico".

La singularidad de esta sentencia reside en la apreciación de la circunstancia eximente incompleta de trastorno mental, de conformidad con los arts. 20.1 y $21,1^{\text {a }} \mathrm{CP}$, al considerar que "la ejecución del hecho estuvo fuertemente influida por el trastorno que padece la acusada, esencialmente porque, como señaló el médico forense en el plenario, si bien entendía la molestia que podría generar emitir ruidos en la intensidad descrita, su propósito de solventar esos problemas a que aludía en su declaración se sobreponía a tal entendimiento. Esto es, que tenía afectada con una intensidad relevante su capacidad de controlar sus actos". Con todo, no se estima adecuada la rebaja de la pena en dos grados, pues para apreciarse la existencia del trastorno no se acredita una intensidad del mismo que justifique tal rebaja de la pena.

La pena impuesta, aplicadas las reglas del concurso ideal y la eximente incompleta, es de dos años y un mes y diecisiete días de prisión y ocho meses de multa, así como inhabilitación especial para oficio o profesión de restauración de un año y seis meses. Se acuerda, además, imponer la medida de internamiento en centro psiquiátrico, conforme a los dispuesto en el art. 96.1,1ำ $\mathrm{CP}$, con un límite máximo de dos años y nueve meses

La segunda sentencia (también condenatoria) por contaminación acústica es la SAP Castellón (Sección 1aㅡ) núm. 2/2020, de 7 de enero. Los hechos probados refieren un supuesto de ruido excesivo procedente de las terrazas de un barrestaurante desde 2012, con reiterada desobediencia de las resoluciones administrativas adoptadas para el cese de la actividad y la orden de clausura y suspensión del funcionamiento de las terrazas del establecimiento. Como consecuencia de los hechos, quedan acreditados distintos trastornos de salud sufridos por cuatro vecinos.

En este caso, y a diferencia de la sentencia recién comentada, los hechos declarados como probados se consideran constitutivos de un delito contra el 
medio ambiente y los recursos naturales en su modalidad de contaminación acústica, habiendo creado un riesgo de grave perjuicio para la salud de las personas y desobedeciendo a la autoridad administrativa, previsto y penado en los artículos 325 inciso último y 326 b) del CP en su redacción dada por la reforma penal de 2010, vigente al momento de los hechos, por resultar más beneficiosa para el reo que la actual operada por LO 1/2015. No se acusa por delito de lesiones en concurso ideal con el delito de contaminación acústica.

Una vez más, la sentencia aplica criterios jurisprudenciales consolidados en la interpretación del artículo $325 \mathrm{CP}$, ya sea en cuanto al tipo objetivo o subjetivo del delito. También aplica jurisprudencia consolidada al no estimar que los hechos probados revistan los caracteres del delito de desobediencia del artículo 556 CP planteado por la acusación particular, "al no poder concurrir este delito con la agravante de desobediencia a la autoridad administrativa del artículo 326.b) CP que sí ha sido aplicada en el presente caso, pues si se volviese a sancionar al acusado por unos mismos hechos que reflejan su desobediencia a las resoluciones administrativas de suspensión de las actividades contaminantes (la providencia judicial acordaba requerir al acusado para el cumplimiento de órdenes administrativas), se produciría una vulneración del ne bis in idem, ya que si la desobediencia da lugar a la agravación del delito medioambiental, no puede de nuevo volver a ser tenida en cuenta para configurar un nuevo delito de desobediencia (STS núm. 875/2006, de 6 de septiembre)".

La SAP Madrid (Sección 16â) núm. 698/2019, de 26 de noviembre, se refiere a un supuesto de contaminación por vertidos. En concreto, queda acreditado que, en una parcela con licencia para verter tierras limpias, se vertían camiones de escombros, que llegaban incluso por encima del nivel de la calle. El acusado, que tenía contrato con la gestora de dicha parcela para su relleno con residuos inertes, es absuelto de un delito contra el medio ambiente previsto en el artículo 325, último inciso, y 326.b) del CP vigente en el momento de ocurrir los hechos (redacción dada por la LO 5/2010, de 22 de junio), que se corresponde con los artículos 325.2.II y 327.b) CP vigentes.

La Sala estima que los hechos no son constitutivos de delito sino de una infracción administrativa. A pesar de que las muestras analizadas dieron positivo 
en fluoruros y en arsénico, las cantidades encontradas se consideran muy distantes de los valores a partir de los cuales se puede considerar que el vertido es peligroso. En este sentido, la Sala todavía añade: "Es cierto que el suelo es permeable, que puede llegar hasta las aguas subterráneas con el proceso de lixiviación y esto puede acarrear un infiltrado de fluoruros y arsénicos en las mismas, pero por la cantidad aparecida en los informes periciales no se puede considerar que integre un grave riesgo ni para el equilibro del medio ambiente ni para la salud de las personas".

Por lo demás, esta sentencia reitera criterios jurisprudenciales conocidos con relación al artículo 325 en la redacción dada en 2010. Así, recuerda: 1) la naturaleza de delito de peligro hipotético; 2) la posibilidad de integrar la norma penal en blanco tanto con disposiciones de rango superior (Directivas y Reglamentos de la Unión Europea, como inferior (Órdenes Ministeriales, Decretos y Órdenes emanadas tanto de la Administración Central como de las autoridades administrativas autonómicas y locales); 3) "que el dolo será normalmente un dolo eventual o de segundo grado, siendo improbable la apreciación del dolo directo, ya que normalmente la conducta potencialmente lesiva del medio ambiente se comete con una finalidad inocua para el derecho penal, como es el desarrollo de una actividad industrial"; y 4) "que la conducta, pese a la forma activa de las locuciones verbales descritas, alcanza sin duda a la comisión por omisión, cuando el sujeto deja, tolera, permite, en suma, que se produzca un vertido y no pone los medios para impedirlo". Todo ello sigue siendo aplicable a la redacción vigente del artículo $325 \mathrm{CP}$, con excepción del primer punto, puesto que actualmente el artículo 325.1 CP también incluye resultados de lesión ("cause o pueda causar").

La segunda sentencia relativa a vertidos, la SJP de Huesca núm. 26/2020, de 4 de febrero, es también absolutoria. Los hechos se refieren a la operación de desembalse de una presa hidroeléctrica que provocó, aguas abajo de la presa, la existencia de abundante lodo, así como un recuento final de animales muertos que arrojó el siguiente resultado: 4471 madrillas, 24 truchas, 2 barbos colirrojos, 1 gobio, 2 piscardos y 1 tritón. El Ministerio Fiscal y las acusaciones particulares consideraron los hechos constitutivos de: A) Un delito contra el medio ambiente y recursos naturales cometido por imprudencia de los artículos 325.1 del CP, en 
su redacción actual, en concurso ideal del art 77. 1 con el art. 330, para todos el 331 en su redacción actual. Y de forma alternativa: B) Un delito contra el medio ambiente y recursos naturales cometido por imprudencia de los arts. 325.1 en su redacción actual en concurso de normas del art. 8.3 con el art. 330, para todos el 331 en su redacción actual.

Aunque no estrictamente novedosa, una de las cuestiones interesantes a destacar de la sentencia es la interpretación del término "vertido". De acuerdo con la Sala, el concepto "vertidos" que emplea el precepto (al igual que el de "emisiones") no puede entenderse al margen de otro concepto que está íntimamente ligado a aquel, que es el de "contaminación”. Citando jurisprudencia del TS, la Sala recuerda que "el significado semántico de algunas de las expresiones comprendidas en el tipo penal como emisiones, vertidos, radiaciones o inyecciones hace pensar que el legislador pretendió compendiar el conjunto de actividades que proyecten hacia las aguas, el suelo o la atmósfera sustancias contaminantes, con independencia de cuál sea el estado de tales sustancias (sólido, líquido o gaseoso)." Con relación a la Ley de Aguas, estima que "queda claro, en cualquier caso, que el vertido de aguas a que se hace referencia es el de 'aguas residuales', pues así se desprende de una interpretación conjunta con los demás preceptos de ese capítulo: art. 101 (instalaciones de depuración), 107 (explotación de las instalaciones de depuración de aguas residuales) y 108 (constitución de empresas de vertido para conducir, tratar y verter aguas residuales de terceros)". A mayor abundamiento, la Sala se refiere a la jurisprudencia del Tribunal Superior de Justicia de la Comunidad Europea, que estableció que el concepto jurídico medioambiental de vertido se refiere a la introducción de sustancias peligrosas en las aguas y concluye: "A la vista de todo ello, la operación de desembalse (y con independencia ahora de si se trató de un vaciado total o solo de rebajar el nivel de agua del embalse hasta el nivel mínimo de explotación) no puede considerarse como un 'vertido' en los términos que exige el tipo penal, pues no se introdujo ninguna de las sustancias peligrosas antes mencionadas, de modo que no se cumple el primer elemento del tipo del artículo 325 CP”.

Tampoco considera la sala que concurre el delito del artículo $330 \mathrm{CP}$, que sanciona a quien, en un espacio natural protegido, dañare gravemente alguno 
de los elementos que hayan servido para calificarlo, con pena de prisión de uno a cuatro años y multa de 12 a 24 meses. De nuevo, es la interpretación de un elemento normativo, en este caso, el concepto de "espacio natural protegido", lo que lleva a la Sala a afirmar la no concurrencia del delito. Sobre la base de normativa europea, estatal y autonómica, se descarta que la zona afectada pueda ser considerada como tal.

Añade la sentencia: "Por lo demás, el resultado típico es el daño grave, elemento valorativo del tipo que debe determinarse con base en criterios o datos objetivos, tales como la extensión de la zona afectada en relación con la superficie total del espacio natural, la mayor o menor posibilidad de regeneración, el número de ejemplares afectados en relación al censo total, etc. El daño al espacio natural debe ser concebido como destrucción de su valor ecológico, de manera que el daño grave a los elementos exigirá algo más que la afectación a varios ejemplares, concretamente un daño global a la especie. Ello permite distinguir este delito de otros, como el delito de caza o pesca de especies amenazadas, e incluso de infracciones administrativas que contemplan la muerte de determinadas especies, y justifica la mayor pena prevista para la conducta del art. 330 frente a la prevista en el art. 334. Y a este respecto hay que decir, no sin antes reiterar que es la no consideración de la zona afectada como espacio natural protegido lo que impide la aplicación del artículo 330 CP que tampoco se sabe con certeza cuál es el grado de afectación de la zona".

Hay que decir que, por si los anteriores argumentos absolutorios no fueran suficientes, la sentencia todavía insiste en la no concurrencia del delito, esta vez por inexistencia de los elementos de la imprudencia grave.

La última sentencia a comentar sobre delitos contra los recursos naturales y el medio ambiente, es la SJP Segovia núm. 24/2019, de 21 de enero, que condena al acusado a un año de prisión, multa de doce meses con una cuota diaria de 6 euros e inhabilitación especial para el cargo de administrador o gerente en empresas dedicadas a la valorización o transformación de residuos por tiempo de dieciocho meses, como autor responsable de un delito de valorización y transformación de residuos previsto y penado en el artículo $326.1 \mathrm{CP}$, así como, por el mismo delito, a la entidad mercantil de la que el acusado era administrador 
único, a la pena de multa de doce meses a razón de 6 euros al día, clausura de los locales y las instalaciones por tiempo de dos años e inhabilitación por tiempo de dos años para obtener subvenciones y ayudas públicas, contratar con el sector público y para gozar de beneficios e incentivos fiscales o de la Seguridad Social.

Los hechos probados refieren la mala gestión de una Planta dedicada a la valorización de residuos no peligrosos, que ha supuesto "un peligro grave para el equilibrio de los sistemas naturales tanto en las aguas como en el terreno pues, en el primer caso, los lixiviados reiterados de la Planta a la Cacera de las Cabras que desemboca en el río Malucas producen un grave riesgo de atrofiación del río, y en el segundo caso, los depósitos de lixiviados y residuos sólidos producidos en los terrenos de las parcelas adyacentes a la planta suponen un riesgo de lixidiación de las aguas subterráneas y de contaminación futura del suelo, además del riesgo biológico que supone la existencia de depósitos de SANDACH mal compostados, especialmente, para la fauna silvestre que se acerque al lugar".

Los hechos fueron calificados provisionalmente por el Ministerio Fiscal como constitutivos de un delito del artículo 326.1 CP, y por las dos acusaciones particulares como constitutivos de un delito del artículo 325.1 CP y de un delito del artículo 325.1 y párrafo segundo del apartado $2 \mathrm{CP}$, respectivamente.

La Sala, acoge la calificación del Ministerio Fiscal y condena por un delito del artículo 326.1 CP. Sin embargo, la sentencia es criticable desde el punto de vista de la argumentación e interpretación del delito. Veamos el porqué.

La Sala aborda, en primer lugar, los elementos del tipo objetivo del delito. Así, establece: "El artículo 326.1del Código Penal sanciona a aquellos que llevando a cabo una actividad de gestión de residuos y contraviniendo las leyes u otras disposiciones de carácter general, produzcan daños materiales a la naturaleza, o lesiones graves o muerte a personas, o puedan producir estos daños o afectar de gravedad el equilibrio de los sistemas naturales. Se trata de una norma penal en blanco, pues la acción ha de efectuarse «contraviniendo las Leyes a otras disposiciones de carácter general protectoras del medio ambiente». Pero se exige algo más que la simple infracción de la norma protectora del medio 
ambiente, que la acción puede perjudicar gravemente el equilibrio de los sistemas naturales".

Como se puede ver, la Sala afirma que en el art. 326.1 CP se exige que la acción pueda perjudicar gravemente el equilibrio de los sistemas naturales. No es exacto. El artículo 326.1 CP contempla distintos resultados típicos de forma alternativa, siendo éste uno de ellos. El delito también se comete cuando la acción cause o pueda causar daños sustanciales a la calidad del aire, del suelo o de las aguas, o a animales o plantas, muerte o lesiones graves a personas. Por remisión al artículo 325.2 CP, la concurrencia de un peligro para el equilibrio de los sistemas naturales determinará una pena más grave. Sorprende, en este sentido, que a pesar de la profusa fundamentación de la concurrencia de este elemento en el caso concreto (al entenderlo como exigencia típica), la pena de prisión impuesta (1 año), no se corresponda con la pena de la modalidad agravada (de 2 a 5 años).

La Sala sigue: "Como dice la jurisprudencia, se trata de un delito de peligro hipotético o potencial, que no requiere un resultado dañoso sino un comportamiento idóneo para causar peligro para el bien jurídico protegido, esto es, la aptitud del riesgo para causar el progresivo deterioro medioambiental. Desde esta perspectiva, lo único que se exige es establecer si el vertido tiene la aptitud para generar tales peligros. No obstante, el delito ha sido configurado por la doctrina jurisprudencial como infracción de peligro concreto y grave. Y para determinar la gravedad del peligro, el Tribunal Supremo (S 27 Ene. 1999) ha señalado que habrá que acudir a la medida en que son puestos en peligro tanto el factor antropocéntrico, es decir, la salud de las personas (incluida la calidad de vida por exigencia constitucional) como las condiciones naturales del ecosistema (suelo, aire, agua) que incluyen por tanto, la fauna y la flora puestas en peligro".

Este párrafo, además inducir a confusión, pues la jurisprudencia citada lo es con relación al artículo $325 \mathrm{CP}$ y no al artículo 326.1 CP, contiene tres inexactitudes: 1) no puede calificarse el delito únicamente como de peligro hipotético. Como acaba de observarse, es también un delito de lesión ("cause o pueda causar"); 2) en ningún caso es aplicable la jurisprudencia antigua que calificaba estos 
delitos como de peligro concreto. Lo hacía sobre la base de una redacción típica distinta del delito ecológico. Además, desde el punto de vista conceptual, es contradictorio con afirmar la naturaleza de peligro hipotético del delito; y 3) cuando la jurisprudencia ha afirmado que para determinar la gravedad del peligro habrá que acudir tanto al factor antropocéntrico como a las condiciones naturales del ecosistema, lo ha hecho con relación al artículo $325 \mathrm{CP}$, en su modalidad agravada de riesgo para la salud de las personas. No tiene sentido este criterio cuando se trata de interpretar la modalidad de peligro para el equilibrio de los sistemas naturales, por más que, por cierto automatismo, sean ya muchas las sentencias que no distingan entre modalidades típicas cuando se remiten a jurisprudencia anterior.

Otra cuestión que sorprende de esta sentencia es la base legal sobre la que se fundamenta la responsabilidad penal del autor. A pesar de que tanto el Ministerio Fiscal como las acusaciones particulares se referían correctamente y de forma expresa a los artículos 27 y $28 \mathrm{CP}$, la Sala fundamenta la responsabilidad del acusado (gestor y administrador único de la Planta) sobre la base del artículo 31 $\mathrm{CP}$, que considera como autor a quien actúe como administrador de hecho o de derecho de una persona jurídica, o en nombre o representación legal o voluntaria de otro, aunque no concurran en él las condiciones, cualidades o relaciones que la correspondiente figura de delito requiera para poder ser sujeto activo del mismo, si tales circunstancias se dan en la entidad o persona en cuyo nombre o representación obre.

Pues bien, es criterio pacífico en la doctrina que el artículo 31 CP es una cláusula de atribución de responsabilidad aplicable únicamente a los delitos especiales ("aunque no concurran en él las condiciones, cualidades o relaciones que la correspondiente figura de delito requiera para poder ser sujeto activo del mismo"), condición que no tiene el artículo 326.1 CP. La base legal para la atribución de la responsabilidad penal del acusado era, efectivamente, los artículos 27 y $28 \mathrm{CP}$, aplicando la teoría del dominio funcional del hecho en el contexto de una persona jurídica (dominio social del hecho). La sentencia analiza la concurrencia de los requisitos de la teoría funcional del hecho, por lo que no puede decirse que se produzca un más que criticable automatismo en la aplicación del artículo 31 CP, pero la base legal sigue siendo errónea. 
Finalmente, cabe destacar que la sentencia condena a la entidad mercantil en aplicación del artículo 31 bis CP, lo cual es positivo desde el punto de vista de una mayor exigencia de responsabilidad de las personas jurídicas, si bien es criticable que la argumentación es inexistente.

\section{DELITOS RELATIVOS A LA PROTECCIÓN DE LA FLORA, LA FAUNA Y LOS ANIMALES DOMÉSTICOS}

En cuanto a los delitos relativos a la protección de la flora, fauna y animales domésticos merece especial referencia la SAP de Navarra (Sección $1^{1}$ ) núm. 239/2019, de 30 diciembre, por la que se resuelve el recurso de apelación interpuesto contra la sentencia dictada por el Juzgado de lo Penal no2 de Pamplona y a la que se dedicó un extenso comentario en la crónica penal correspondiente al anterior semestre (abril-octubre 2019). En aquel momento se destacó la relevancia de la sentencia por el minucioso examen al que el Juez de lo Penal sometía la gravedad de las conductas enjuiciadas y el impacto del resultado, así como por tratarse de una de las escasas sentencias en las que se aplicaba una condena de prisión superior a dos años para los autores de delitos contra la fauna. La sentencia dictada ahora por la Audiencia de Navarra estima parcialmente el recurso de apelación interpuesto por los acusados. Sin embargo, y ello es importante, mantiene la calificación jurídica de los hechos y refuerza, de esta forma, los argumentos del juez de instancia relativos a la antijuridicidad de las conductas perpetradas por los autores. Nos referiremos, en primer lugar, a los hechos cometidos y a la calificación jurídica de los mismos por parte de la Audiencia, para apuntar, en segundo lugar, los cambios que la nueva resolución introduce y que se limitan a la penalidad aplicada.

Los hechos declarados probados atribuyen a tres sujetos vinculados a sociedades de cazadores la colocación de veneno que, en el año 2012 en los cotos de caza de Tudela y Cintruénigo (Navarra), ocasionó la muerte de un gran número de aves, entre las cuales 117 aves rapaces (108 milanos negros, 4 milanos reales, 2 buitres leonados, 1 alimoche, 1 aguilucho lagunero y 1 busardo ratonero) y 4 cuervos. Varias de las aves aparecieron en espacios naturales protegidos y todas las rapaces envenenadas están incluidas en el Listado de Especies Silvestres en Régimen de Protección Especial y del Catálogo Español 
de Especies Amenazadas. Así, es importante subrayar que el milano real está catalogado como especie en peligro de extinción; el alimoche, como especie vulnerable; y el milano negro, el buitre leonado, el aguilucho lagunero y el busardo ratonero, como especies en régimen de protección especial. La causa de la muerte fue en todos los casos, salvo el de un milano negro, el envenenamiento con las sustancias fentión y demetón S-metil, ambas prohibidas en España desde hace años. Tales sustancias fueron colocadas en acciones repetidas durante al menos tres meses en el dormidero de milanos.

La sentencia da por probado que el número de aves encontradas muertas, sobre todo en el caso de los milanos negros, supone una repercusión ambiental muy considerable en la población del sur de Navarra, teniendo en cuenta que: a) Probablemente murieron más ejemplares de los localizados, al existir numerosos factores que dificultan el hallazgo de cadáveres, como la cobertura vegetal que puede ocultarlos, la rápida detección y consumo por animales carroñeros y la dispersión a distancias lejanas antes de producirse la muerte. b) Las fechas en las que sucedieron los envenenamientos coincidían con el periodo de reproducción del milano negro y del alimoche, por lo que la muerte de algunos de los animales ha supuesto también la de los pollos que estuvieran criando, o la no eclosión de los huevos. c) Tras los procesos de envenenamiento el ecosistema se empobrece en grandes predadores, como las rapaces, las cuales, debido a sus parámetros demográficos y a su papel en las cadenas tróficas, tienen poca capacidad de recuperación tras soportar perturbaciones; en cambio, las poblaciones de predadores oportunistas se recuperan en breve tiempo, incluso hasta densidades mayores a las existentes antes de la aparición del veneno, debido al 'efecto llamada' de una zona libre de competencia y al aumento de las especies presa. El ecosistema en su conjunto tiende con ello a empobrecerse; solo una evolución lenta devuelve al cabo de años la situación al grado ecológico de complejidad y riqueza primitivo.

En sus alegaciones, los recurrentes cuestionaron que los hechos imputados pudieran ser constitutivos del tipo penal del artículo $334 \mathrm{CP}$, por cuanto afirmaban que las aves fallecidas no son propiamente especies amenazadas, rechazaban la concurrencia del artículo $336 \mathrm{CP}$ por cuanto no se realizó acto de 
caza alguno, y denunciaban la aplicación del tipo muy cualificado del artículo 338 por la afectación a un espacio natural protegido.

Frente a ello, la Sentencia de la Audiencia afirma la concurrencia del artículo 334 CP. Da por sentado que todas las rapaces objeto de envenenamiento están incluidas en el en el Real Decreto 139/2011, de 4 de febrero para el desarrollo del estado de especies silvestres en régimen de protección especial y del catálogo español de especies amenazadas, en unos casos como especie en peligro de extinción, en otros como especie vulnerable, o como especies en régimen de protección especial. $\mathrm{Y}$ así, puesto que algunas de las aves envenenadas están catalogadas como especies en peligro de extinción, procede la aplicación del artículo 334.2 CP. Al respecto, establece la sentencia que "Los animales muertos por envenenamiento son 108 ejemplares de milanos negros, especie catalogada nacionalmente como en régimen de protección especial (RD 139/2011), la pérdida de estos ejemplares tiene una repercusión ambiental muy considerable, ya que los hechos sucedieron en periodo de reproducción y su densidad en la zona en que ocurrieron los hechos es inferior a la que debiera, en un estado favorable de conservación. Se encontraron envenenados 4 ejemplares de milano real que han sido catalogados como en peligro de extinción en el catálogo nacional de especies amenazadas, recogido en el citado Real Decreto; en cuanto a 1 alimoche es una especie catalogada nacionalmente en situación del más alto riesgo (vulnerable), también han muerto envenenados 1 aguilucho lagunero, especie consideraba vulnerable en el catálogo de especies amenazadas de Navarra y está incluida en el listado de especies silvestres en régimen de protección especial del catálogo nacional, 2 buitres leonados, 1 busardo y cuervos comunes, son todas especies catalogadas.

En cuanto a la aplicación del artículo $336 \mathrm{CP}$, relativo a la utilización de un medio no selectivo para la caza como es el veneno, la Audiencia rechaza la pretensión del recurrente de alegar que los hechos no estuvieran vinculados a la caza por cuanto que asevera que éste era precisamente el móvil que guiaba a los autores. La sentencia da por sentado, en este sentido, que "que los hechos están vinculados a la caza es un extremo que no puede obviarse, ya que para cazar las especies que se aprovechan en el coto los autores de los hechos decidieron eliminar las rapaces mediante envenenamiento, cometiendo un delito de peligro". 
Asimismo la resolución de la Audiencia da por acreditada la afectación de espacios naturales protegidos, por lo que considera de aplicación lo dispuesto en el artículo 338 CP que lleva a la imposición dela pena superior en grado a la respectivamente prevista en cada tipo.

Entre los artículos 334 y 336 el Tribunal establece un concurso medial que, en atención a la regla contemplada en el artículo 77 CP en su versión previa a la reforma de 2015, establece la aplicación de la pena prevista para la infracción más grave en su mitad superior. Mantiene, asimismo la resolución, la atenuante de dilaciones indebidas.

Por consiguiente, en cuanto a la calificación asignada por el tribunal de instancia a las conductas perpetradas por los sujetos, no se detectan cambios en la nueva resolución dictada por la Audiencia. Y sin embargo, como se ha señalado anteriormente, sí se admite parcialmente el recurso de apelación interpuesto, en el sentido de optarse en la nueva resolución por aplicar la pena alternativa de multa que ambos tipos penales, el 334 y el 336 contemplan, junto a la de prisión. Para justificar esta decisión la Audiencia refiere en relación con uno de los acusados la edad del mismo para declarar la innecesaridad de imponer una privación de libertad. Aduce, en este sentido, que "aun apreciando la gravedad de los hechos enjuiciados, no puede obviarse que quien recurre tiene 75 años y ha sido condenado a dos años y ocho meses de prisión, accesoria de inhabilitación especial para el derecho de sufragio pasivo durante el tiempo de la condena; cinco años y cuatro meses de inhabilitación especial para la gestión del aprovechamiento cinegético de cotos de caza, para el oficio de guarda de caza y para el ejercicio del derecho cazar, además de la condena indemnizar de forma conjunta y solidaria por los daños y perjuicios causados y al abono de la cuarta parte de las costas del juicio". De esta forma, la valoración de las penas en su conjunto en combinación con la edad del condenado se presenta como una importante limitación para la comisión de nuevos delitos de esta naturaleza. Señala así la Audiencia que valora no imprescindible "que el reproche penal conlleve la privación de libertad del recurrente y siendo alternativa la imposición de la pena prisión o de la pena de multa, consideramos pertinente estimar en este punto el recurso de apelación interpuesto y en consecuencia modificar la 
sentencia de instancia a los únicos efectos de la imposición de la pena que seguidamente se determina".

Sin embargo, en relación con el resto de acusados, la Audiencia ya no se refiere a la edad de los mismos como elemento para valorar la innecesaridad de la pena privativa de libertad sino que reproduce exclusivamente la segunda parte de la argumentación vertida en el primer supuesto y establece que "teniendo en cuenta la imposición de las penas en su conjunto con las limitaciones que conllevan, que de suyo dificultan en parte la comisión de nuevos delitos de esta naturaleza por las inhabilitaciones que suponen, se aprecia por el Tribunal que no resulta imprescindible que el reproche penal conlleve la privación de libertad de los recurrentes y siendo alternativa la imposición de la pena prisión o de la pena de multa, consideramos pertinente estimar en este punto el recurso de apelación interpuesto y en consecuencia modificar la sentencia de instancia a los únicos efectos de la imposición de las penas que seguidamente se determinan".

En definitiva, la Audiencia mantiene la calificación jurídica de los hechos enjuiciados, reitera la gravedad de la conducta y el nefasto impacto para las aves y para los ecosistemas, pero concluye que la pena privativa de libertad no es imprescindible en supuestos como el examinado y reconduce la sanción a una pena de multa de 30 meses a razón de una cuota de 8 euros al día (7200 euros) y 5 años inhabilitación especial para la gestión del aprovechamiento cinegético de cotos de caza, para el oficio de guarda de caza y para el ejercicio del derecho cazar, debiendo además indemnizar de forma conjunta y solidaria a la Comunidad Foral de Navarra por las aves envenenadas en un total de 57.576,97 $€$, por los gastos derivados de la investigación de los hechos en la cantidad de 3.961,68 euros y en la cantidad 6.000 euros por el coste de las medidas necesarias para restaurar el equilibrio ecológico, manteniendo el resto de los pronunciamientos contenidos en la resolución apelada y declarando de oficio el pago de las costas causadas en esta alzada por su recurso.

Nos referiremos a continuación a dos sentencias relativas a la aplicación del artículo $335 \mathrm{CP}$ en relación con los delitos contra la fauna por actividades de caza. En la SAP de Badajoz (Sección 3로) núm. 195/2019, de 24 de octubre, se revoca la inicial sentencia absolutoria dictada en el supuesto de dos individuos 
que fueron hallados juntos ejerciendo la caza menor sin autorización del titular del coto. La sala acoge la tesis del Ministerio Fiscal que alega que "no excluido del régimen cinegético especial que supone un coto de caza, sin que tampoco conste en el procedimiento atisbo alguno de que en dicho coto existiera alguna zona enclavada excluida de dicho régimen cinegético especial, los hechos deben ser subsumidos y penados según lo previsto en el art. 335.2CP”. Así, se mantiene en la resolución que "(I)a figura delictiva mencionada consiste en cazar - pescar especies no amenazadas (la caza de las especies protegidas especialmente o amenazadas se castiga en el artículo 334) "en terrenos públicos o privados ajenos, sometidos a régimen cinegético especial, sin el debido permiso de su titular", todos cuyos requisitos se cumplen en este caso, por cuanto que, como se ha dicho, el único punto que se discute es la determinación legal del coto de caza como terreno sometido a régimen cinegético especial."

Que la cuestión resulta espinosa puede comprobarse comparando el fallo de la sentencia mentada con el de la SAP Madrid (Sección 7ª̣) núm. 681/2019, de 21 de octubre, dictada en el mismo periodo, y por la que se revoca la sentencia condenatoria de instancia y se decreta la absolución respecto de los dos individuos que fueron hallados cazando, careciendo de autorización administrativa para ello, en zona calificada como terreno de aprovechamiento cinegético común, estando prohibida (vedada) la actividad de caza en el mismo en virtud del art. 9.5 de la Orden de Caza 2015-2016 de la Consejería de Medio Ambiente de la Comunidad de Madrid 591/15 de 23 de abril, y pudiendo cazar únicamente con la autorización por escrito concedida por la Comunidad de Madrid en supuestos excepcionales. En este caso los sujetos fueron condenados por un delito de caza prohibida del art. 335.1 y .4 CP y alegaron en el recurso formulado, error en la aplicación de este precepto. La Audiencia acude en este caso a la STS núm.187/2006, de 23 de febrero, que señala que ""la captura de un ejemplar en una especie cuya caza está autorizada previa licencia o permiso especial, careciendo del mismo o fuera de los límites geográficos, temporales o cuantitativos administrativamente establecidos, constituye una infracción administrativa, pero no se integra en el artículo 335 del Código Penal, pues éste concreta su prohibición a la caza o pesca de especies no expresamente autorizadas, y no puede extenderse a otros supuestos distintos no comprendidos 
expresamente en el mismo". Y prosigue la misma, diciendo "quedan fuera del ámbito del tipo, según la doctrina expuesta, las actividades de caza o pesca respecto de especies que, no estando incluidas en el artículo 334, esté prevista de alguna forma alguna posibilidad de autorización. No se sanciona en realidad la falta de autorización administrativa, sino una conducta atentatoria al medio ambiente al producir efectos negativos sobre determinadas especies de flora y fauna respecto de las cuales no esté prevista la posibilidad de realizar tal conducta mediante la oportuna autorización administrativa".

Por ello, la Sala adopta un criterio interpretativo de carácter restrictivo del tipo penal y considera excluido del ámbito del tipo las actividades de caza o pesca respecto de especies que no están incluidas en el art.334 $\mathrm{CP}$, esto es, especies efectivamente amenazadas, respecto de las cuales esté prevista alguna posibilidad de autorización. En definitiva, el precepto no sanciona la falta de autorización administrativa, sino la conducta atentatoria al medio ambiente por la producción de efectos negativos sobre determinadas especies respecto de las que no está prevista la posibilidad de realizar tal conducta mediante autorización administrativa.

En relación con el artículo $336 \mathrm{CP}$, destacamos en este periodo la SAP de Castellón (Sección 2), núm. 2/2020, de 23 de diciembre, en la que se absuelve al acusado precisamente por la valoración del carácter de método selectivo -0 no- del instrumento empleado para la caza. A diferencia del método de caza denominado "parany", respecto del que la Audiencia de Castellón ya ha declarado en diversas resoluciones su carácter prohibido, en el presente caso, se analiza un dispositivo de jaula accionada a mano a través de un cordel que hace caer el palito en forma de "U" o de "V" que sostiene el lateral por donde habría de entrar el pájaro. En este supuesto, la sala acepta las alegaciones del acusado en relación a que el método requiere presencia, atención por parte del sujeto, que domina en todo momento la oportunidad y el funcionamiento, y posibilita la liberación inmediata y sin daño para el animal. La sentencia califica el método como "muy simple, limpio y en verdad inofensivo, absolutamente alejado de los métodos o instrumentos no selectivos y no reparadores que suponen otras modalidades de atrapamientos automatizados y de dudoso control dañino que sí merecen reproche penal", y en consecuencia excluye la 
intervención penal y absuelve al acusado, sin perjuicio de consideraciones que desde el ámbito administrativo puedan realizarse.

En último término, en relación con el delito de maltrato animal previsto en el artículo $337 \mathrm{CP}$, nos referiremos a la SAP de Barcelona (Sección 9ª) núm. $575 / 2019$, de 25 de noviembre, por la que se condena por un delito de maltrato leve al individuo que disparó con una escopeta de balines al perro de su vecino. Señala la resolución, que la actuación "reúne todos los elementos del delito leve de maltrato animal, entendiéndose que el maltrato cruel viene determinado por la gratuidad de la acción de disparar contra el perro del vecino con el que existe además un enfrentamiento evidente no solo a la vista del litigio civil precedente sino por la existencia de otra denuncia del sr. Victorino contra el padre del sr. José Carlos. En consecuencia, procede condenarlo como autor de un delito leve de maltrato animal previsto y penado en el art. 337.4 del Código Penal por haber ejecutado directa y materialmente los hechos relatados, conforme disponen los artículos 27 y 28 del código Penal".

Finalmente, respecto del artículo 337bis CP, relativo al abandono de animes, destaca la SAP Oviedo (Sección 3 $3^{\text {a }}$ ), núm. 104/2020, de 28 de febrero, en la que se condena por este delito un supuesto que describe una situación de desatención y abandono de los animales de los que la acusada era propietaria, sin proveer y sin procurarles, bien por ella misma o por terceros, alimentación y cuidado, omitiendo la acción esperada a la que estaba obligada, su alimentación y cuidados adecuados, necesarios para procurar su bienestar, estando encerrados los animales sin alimento y sin apenas agua durante días y con altas temperaturas lo que lógicamente les hubo de causar mucho sufrimiento. El delito de abandono se configura como un delito de peligro que no requiere de la producción de ningún resultado, de forma que si el abandono activo u omisivo determina que la situación de riesgo se materialice en lesiones, lo que no ocurre en el supuesto, la conducta debería ser calificada como delito de maltrato del art. $337 \mathrm{CP}$. 